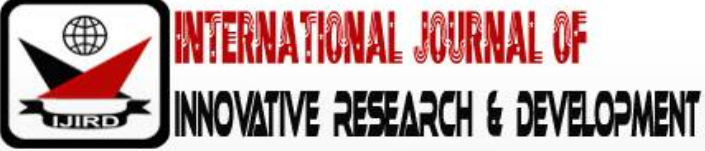

ISSN 2278 - 0211 (Online)

\section{Academic Achievement of Direct-Entry and Non-Direct Entry (Pre-NCE) Science Students in Niger State College of Education, Minna Nigeria: Implications for Educational Administrators}

\begin{tabular}{|c|} 
Babatunde, Abdullateef Eyitayo \\
Ph.D. Candidate, Department of Educational Technology, \\
Federal University of Technology Minna, Niger State, Nigeria \\
Chukuwuemeka, Emeka Joshua \\
Ph.D. Candidate, Department of Educational Technology, \\
Federal University of Technology Minna, Niger State, Nigeria \\
Abdulrahim, Musbahu \\
Ph.D. Candidate, Department of Science Education, \\
Federal University of Technology Minna, Niger State, Nigeria \\
Adai S. Ibrahim \\
Professor, Department of Science Education, School of Science \& Technology Education, \\
Federal University of Technology, Minna, Nigeria
\end{tabular}

\section{Abstract:}

The study investigates the academic achievement of direct entry and Non-direct entry (Pre- NCE) science students in Niger State College of Education, Minna based on their modes of admission into NCE I, NCE II, and NCE III programme. The study adopted an expost-facto research design. The population of the study consisted of all students admitted in the school of sciences into the Niger state college of education, Minna during 2008/ 2009 academic sessions. Altogether they were 1110 admitted in the college during the years under study. A three years track of academic performance rating of 372 students in selected courses in the school of sciences were used for the study. The findings revealed that there is a significant difference between the mean scores of academic achievements of Direct Entry and Non-direct entry (Pre-NCE) NCE I, NCE II, and NCE III students in the school of sciences at the Niger State College of Education, Minna. It is therefore recommended that the PostUTME test introduced by colleges of Education should be sustained especially as cases of students having a GPA of 0.00 have been recorded among UTME students who came in through Direct Entry.

Keywords: Academic, achievement, direct entry, non-direct entry, students, educational administrators

\section{Introduction}

The realization that education is an instrument for national development has compelled the federal government of Nigeria to make education at the primary school level free to every Nigerian irrespective of the socio-economic status. With the recognition of education as a veritable key to individual and national development, the rate at which people tend to clamour for education especially tertiary education has increased. A sizeable number of candidates apply for admission into colleges of education every academic session with only a small percentage securing admission due to lack of enough spaces and or failure to meet given prerequisite (Quadri \& Olowo, 2013).

According to National Commission for Colleges of Education (NCCE, 2009), eligible candidates for admission into 100 level in the colleges of education must possess five credits passes in not more than two sitting at West African School Certificate Examination (WASCE) or the National Examination Council (NECO). English Language and Mathematics must be passed at credit level, and two credits must be in the areas of candidates' specialization. These are the students who were admitted into the 100 level programme of the college after possessing the prerequisite qualifications as stipulated by the college and NCCE considered as direct entry students. In view of the constant deficiencies recorded by students in ordinary level examinations, and high demand for qualified science teachers, non-direct entry (Pre-NCE) programme was introduced by a few colleges of education.

In an effort to improve admission rate into the colleges of education, the National Commission for College of Education (NCCE) introduced the Non-Direct entry (PRE-NCE) Programmed to admit students with ordinary level examination deficiencies. This is a college programme approved by the NCCE to prepare students who may have certain deficiencies to qualify them for 100 level courses. The candidates who gained admission by Non-Direct entry (Pre-NCE) were those who possessed two credit passes and three ordinary passes at one sitting in Senior Secondary Certificate 
Examination (SSCE) by West African Examination Council (WAEC) or National Examination Council (NECO), or one credit pass and four ordinary passes at two sittings (NCCE, 2003). English language and mathematics must be passed.

At the inception of Nigeria Certificate in Education (NCE) programme, a science programme was included in order to obtain qualified science teachers to teach science courses at the primary and junior secondary schools. The science programmes are offered in various combination of courses such as Chemistry/Physics, Mathematics/Physics, Biology/Chemistry, Physical Health Education (PHE), Integrated Science, Mathematics/Computer, Physics/Computer Mathematics/ Chemistry.

According to the National Commission for Colleges of Education (2007), the Pre-NCE programme has tremendously improved the admission rate in the colleges of education and probably improved the academic performance of the students concerned. The Pre-NCE programme is as a result of few candidates who indicate interest in seeking admission through the joint matriculation examination into the Colleges of Education in Nigeria, leading to a situation which threatens the continued existence of the pre-NCE programme to serve as an intervention strategy for ready intakes into NCE programme. The objectives of the pre-NCE programme as stated in the pre-NCE manual are;

- To produce a continuous flow of students into the NCE programme in areas of acute student shortage in terms of minimum entry qualification.

- To assist students with academic deficiency, make advancement in their studies.

- To feed the NCE programme with student input in the area of language science and vocational education where there are death qualified candidates; and

- To assist students who hitherto had academic deficiencies compare favourably with their counterparts on the NCE programme.

The objectives of the programme cannot be realised in isolation; they have to do with the context under which the students are learning. Some of these include the qualifications of programme participants, the student-lecturer ratio, which affects the demand on lecturers and the quality of the curriculum and the degree of congruence of the curricula content with the ordinary level syllabus of examining bodies so that deficiencies can be addressed.

Akinbote (2007) asserted that those who enroll to train as teachers are usually not the best materials. They further said that students, who enroll to train to become Teachers, do so because they cannot cope with other courses. It is against this background that the National Commission for Colleges of Education (NCCE) approved the mounting of preNCE programme to take care of those students who fall below the admission requirement for science, technical and language education course with a view to meeting the admission quota and ascertain continuous manpower flow into the stream of the teaching profession in these specialized field that are pertinent to national growth and technological advancement.

Academic achievement has been viewed as a scholastic performance of individual tested during (Formulae) or after (Summative) a particular programme of study. The Nigerian public is disenchanted with the teacher's performance. Not only the public, but even educators also had little faith in the kind of academic performance and achievement by Nigerian students (Okebukola, 2007).

The Direct Entry Students are those who possess the 5 credits as pre-request and meet the cut-off mark in the matriculation examination conducted by the Joint Admission and Matriculation Board (JAMB). The entry qualifications of the Pre-NCE and Direct Entry students are therefore different. In the Niger State College of education Minna, (though this is peculiar to Niger State College of Education) for a candidate to gain admission into Pre-NCE programme, the candidates must have possessed two credit passes and three ordinary passes; one of the credit passes should be either English Language or Mathematics and one other credit passes should be in the area of study.

The pre-NCE students traditionally spend one year (2 semesters) at the pre-NCE level before transiting to 100 levels. During the pre-NCE programme the students are taken through a number of courses which are in the main preparatory for 100 levels and the entrance examination into the college of education conducted by JAMB.

At this point, the need for qualified science teachers at the primary and junior secondary school cannot be overemphasized. As a matter of fact, without qualified science teachers, the national desire of becoming scientifically developed country cannot be achieved. The shortage of qualified science teachers throughout all levels of our educational system has become a major concern for the country. The introduction of pre-NCE Science programme has boosted the enrollment of science students and thereby increasing the production of more qualified teachers. There is obviously very low participation of women in mathematics and other science-related subjects. Ado (2010) showed that the level of participation of females in mathematics, science and technology programmes in Nigerian universities in 1989 was as low as $21 \%$. The problem of difference in gender performance started from gender strew typed choice. According to a study conducted in the summer period in England, it was discovered that girl's performance was high in English, history, and language, domestic and commercial subjects (Erinosho, 2005). The only science subject in which girls achieve the majority passes was biology. This implies that boys perform better than girls in all subjects except in biology. In 1986, a study conducted in England by the department of education revealed that at a higher level of attainment, boys are skill achieving proportionally for better results than girls in Mathematics and Science subjects.

Based on this premise, there is a need to determine whether or not there is a difference between the academic achievement of Direct Entry and pre-NCE students in science courses.

\subsection{Statement of the Problem}

There are no empirical data to be used in assessing the instructional criteria for the intake of pre-NCE students at the Nigerian Certificate in Education programme. In 2010, Dahiru carried out a study that was limited to NCE 1, NCE II and NCE III level students at the Federal College of Education, Katsina. Consequently, the relationship between the 
performances of Non-Direct Entry (Pre-NCE) students of Niger State College of education, Minna as compare to those who gained admission through Unified Tertiary Matriculation Examination (UTME) has been identified as an area of concern. As such, there is a need to examine the academic achievement of Direct Entry and Non-Direct Entry (Pre-NCE) students by different modes of entry into some selected science subjects in Niger State College of Education, Minna.

\subsection{Aim and Objectives}

The purpose of the study is to collect, track and compare academic achievements of Direct Entry and Non-Direct Entry (Pre-NCE) students who were admitted into science programs at the Niger State College of Education using different levels of preparation for the courses for three years (i.e. NCE I, NCE II, NCE III).

\subsection{Research Question}

For this study answer will be sought to the following research questions:

- Is there any difference in the academic achievement of science students admitted through Direct Entry and NonDirect Entry (Pre-NCE) programme at the end of NCE I?

- Is there any difference in the Academic Achievement of science students admitted through Direct Entry and NonDirect Entry (Pre-NCE) Programme at the end of NCE II?

- Is there any difference in the Academic Achievement of science students admitted through Direct Entry and NonDirect Entry (Pre-NCE) Programme at the end of NCE III?

\subsection{Research Hypotheses}

The following null hypotheses will be used to determine whether or not differences exist between the research questions.

- $\mathrm{HO}_{1}$ : There is no significant difference in the academic achievement of science students admitted through Direct Entry and Non-Direct Entry (Pre-NCE) programme at the end of NCE I at Niger State College of Education, Minna.

- $\mathrm{HO}_{2}$ : There is no significant difference in the academic achievement of science students admitted through Direct Entry and Non-Direct Entry (Pre-NCE) Programme at the end of NCE II at Niger State College of Education, Minna.

- $\mathrm{HO}_{3}$ : There is no significant difference in the academic achievement of science Students admitted through Direct Entry and Non-Direct Entry (Pre-NCE) Programme at the end of NCE III at Niger State College of Education, Minna.

\subsection{Significant of the Study}

The significance of the study includes the followings:

- The results from this study will help to provide clear evidence if (any) of the Pre-NCE programme is improving academic achievement for NCCE

- The results will aid or assist policymakers in making a decision about Pre-NCE and admission related issues

- The information from this study will add to the body of knowledge regarding Colleges of Education in Niger State.

\section{Literature Review}

\subsection{Academic Performance of Students and Modes of Entry}

Oluwatayo (2003) and Adonis (2005) performance in advance level paper correlated with academic performance in their entry qualification, the study clearly showed that positive and significant relationship existed between the entry characteristics ( SSCE, ND and NCE) and the academic performance (CGPA) of university undergraduates; However, a very low and positive relationships existed between CGPA and NCE and also between CGPA and ND. This is not surprising because the two categories of direct entry students had experienced post-secondary (intermediate) tertiary institutions of learning whereby they had been exposed to semester course system and were aware of the intricacies in semester course system. They have already become experienced, test wise and matured for university education.

It was also observed that direct entry (200 levels) performance generally better academically than 100 level students and their result showed appreciable improving performance on average as they progressed. Students that did 100 levels did not show appreciable progress as they maintain the same level of performance e.g. 1st, 2nd year and 4th, 5th years. However, those that joined in 300level had the highest grade of 3.28 at 3rd and 4th years but dropped behind those that joined at 200level in their final year. Nigeria students that qualified to proceed are those having Grade point average of 1.00 and above on five-point grading scale at the end of a given session. A student will be on probation if he/ she scores less than 1.00 GPA at the end of a session for the first time. NUC, (2005)

Lawal (2000) conducted a study which examined student's performance in Education Courses, by looking at West African Examination Certificates (WAEC), General Certificates Examination (GCE), Grade II and National Examination Council (NECO) as entry qualifications. The findings revealed that none of these four (4) entry qualifications is more superior to the others in affecting student's performance in education courses. Omwirhiren (2002), argued that "Generation of any meaningful instruction must begin in the classroom"; and if the placement is properly done using a well-organized entry qualification method(s) the student's competence will be the case of wrongful placement which is the root cause of the breakdown of meaningful instruction. Thereby, leading to failure and defeat of the real essence of selection through entry qualification, performance, and accredited results from such examinations such as Pre-NCE, WAEC, GCE, NECO, NABTEB and Grade II. Samuel (2012) revealed that the students' entry qualifications could be used to predict their final performance in the National Certificate of Education Programme. 
Simon (2010) revealed that in the case of College of Science, Agricultural and Science Education with four Departments, the CGPA ranged from 0.39 - 4.15 for remedial students while for UME, the GPA ranged from 0.00 - 4.47. The mean GPA of 1.99 and a standard deviation of 0.79 was recorded for Remedial students while 2.02 and 0.90 respectively were recorded for UME. The lowest GPA of 0.00 and highest GPA of 4.47 were recorded for UME. The range of 3.76 for Remedial and 4.47 for UME results indicated that the Remedial Achievement was more consistent than the UME which indicates unpredictability.

Considering the Bachelor of Agriculture (Agric. Economics and Extension) programme, the GPA ranged from 0.13 to 3.63 for Remedial Students while for UME, the GPA ranged from 0.25- 4.25 of 0.72 was recorded for Remedial Students. While corresponding 1.96 and 1.01 respectively were recorded for UME. However, the smaller range of 3.50 for Remedial compared to 4.00 for UME results indicates that the Remedial Achievement was more consistent than UME which indicates unpredictability.

In the case of the Bachelor of Agriculture (Animal Production) programme, the GPA ranged from 0.25-3.25 for Remedial students while for UME, the GPA ranged from 0.33-3.33. The mean GPA of 1.51 and a standard deviation of 0.70 was recorded for Remedial students while 1.53 and 0.76 respectively were recorded for UME. The lowest GPA was recorded for Remedial; the highest GPA was recorded for UME. The smaller range of 2.00 for Remedial compared to 3.00 for UME results indicates that the Remedial Achievement was more consistent than the UME. This indicates unpredictability. For the B.Eng. (Agricultural Engineering) programme, the GPA ranged from 0.61 to 4.00 for Remedial Students while for UME, the GPA ranged from 0.72 - 4.61. The mean GPA of 2.34 and a standard deviation of 0.87 was recorded for Remedial Students while 2.86 and 1.04 respectively were recorded for UME. The lowest GPA was recorded by Remedial the highest was recorded by UME; however, the smaller range of 3.39 for Remedial compared to 3.89 for UME results indicates that the Remedial Achievement was more consistent than the UME which indicates unpredictability.

For the Bachelor of Science (Food Science and Technology) programme the GPA ranged from 0.58-3.04 for Remedial students while for UME, the GPA ranged from 0.46-3.54. The mean GPA of 1.69 and a standard deviation of 0.76 was recorded for Remedial students while 1.74 and 0.92 respectively were recorded for UME whereas the lowest and highest GPA was recorded for UME, the smaller range of 2.46 for Remedial compared to 3.08 for UME results indicates that the Remedial Achievement was more consistent than the UME which indicates unpredictability.

\section{Methodology}

The design employed for this research was ex-post- facto as the researchers did not have control over some of the variables in their natural settings. This design can be used when all the variables examined had already occurred and are not to be manipulated (Lawal, Badu \& Chukwuemeka, 2015).

\subsection{Population of the Study}

The population of the study consisted of all students admitted into the Niger state college of education Minna during the 2008/ 2009 academic session. Altogether they were 1110 admitted in the college during the years under study. There are two modes of admission to the NCE programme. These are Direct Entry (DE) or Non- direct entry (pre.-NCE) mode. This program involved a combination of courses such as Mathematics/Physics, Physics/Chemistry, Biology/ Chemistry, Mathematics/ Computer as well as Integrated Science (double major) students. See the table below:

\begin{tabular}{|c|c|c|c|c|}
\hline & \multicolumn{3}{|c|}{ Passing Rate } & Total \\
\hline Annual progress & Entry Type & $\%$ Pass & $\%$ Fail & 100 \\
\hline $2008 / 2009$ & Non-Direct Entry (79) & $96.2(76)$ & $3.8(3)$ & \\
$(100$ Level) & Direct Entry (291) & $85.1(248)$ & $14.9(43)$ & 100 \\
\hline $2009 / 2010$ & Non-Direct Entry (79) & $93.6(73)$ & $6.4(5)$ & 100 \\
& Direct Entry (291) & $83.2(243)$ & $16.8(49)$ & 100 \\
\hline 200 Level) & Non-Direct Entry (79) & $93.7(74)$ & $6.3(5)$ & 100 \\
& Direct Entry (291) & $84.2(245)$ & $15.8(46)$ & 100 \\
\hline
\end{tabular}

Table 1: Progression of NCE Science Students for 2008/ 2009 Academic

Session at Niger State College of Education Minna

Source: Academic Planning and Development Office of NCOE Minna

The following were the list of subject combinations in which students were admitted within the school of sciences, Niger State College of Education Minna; Mathematics/Physics, Biology/Chemistry, Physics/Chemistry, Mathematics/ Computer and Integrated science (double major).

\subsection{Sample and Sampling Techniques}

In order to ensure adequate representation of the department in the school of science of the Niger State College of Education Minna. A list of students enrolled through Pre-NCE programme was collected from the Directorate of Pre-NCE of 2007/ 2008 academic session. Similarly, a list of students enrolled to 100 level of 2008/2009 academic session was obtained from the Academic Secretary Office of the college. Although the list of the 100 level students admitted at every academic session does not indicate the mode of entry, the researcher was able to trace those students admitted through Pre-NCE from the Student Admission lists collected from the Office of the Directorate of Pre-NCE of the college. 
Finally, stratified random sampling was employed for the selection of the subjects of participants. The stratification was based on: the graduation year and random sampling were employed for the selection of school in the college. A three years track of academic performance rating of 372 students was conducted from 2008/2009 to 2010/2011 session which consisted of 215 male (58.1\%) and 155 female (41.9\%) students. Sampled from this list were 26 (7.0\%) students from Mathematics/ Physics for Direct Entry (DE) mode and 10 (2.7\%) Non-Direct Entry (Pre-NCE) mode students, making a total of 36(9.7\%). Biology/ Chemistry students consists of 147 (39.5\%) were direct entry (DE) mode and 24 (6.5\%) were non- direct entry (Pre-NCE) mode making a total of 171 (46.0\%). For the Department of Mathematics/Computer, 72(19.4\%) students were direct entry (DE) mode and 24 (6.4\%) students were Non- direct entry (Pre-NCE) mode making a total of $96(25.8 \%)$. For the department of Physics/ Chemistry, 17 (4.6\%) students are direct entry (DE) mode, and 6 $(1.6 \%)$ were Non- direct entry (Pre-NCE) mode making a total of $23(6.2 \%)$. For the department of Integrated Science (double major) students, 30 (8.1\%) were from direct entry (DE) and 16 (4.3\%) were Non- direct entry (Pre-NCE) mode making a total of $46(12.4 \%)$ in their final year.

\subsection{Method of Data Collection}

This researcher submitted a letter of request and further follow-ups through the Academic Secretary Office and the Academic Planning and Development Office (APD) for data of the students. The Student total cumulative grade point average (CGPA) at the end of their graduation year under study were collected and grouped under either Non-Direct Entry (Pre-NCE) and Direct Entry (DE). The students' records were personally screened with the help of the Chief Examiner in Academic Planning and Development Office of Niger State College of Education Minna. The data was based on the academic performances of the following five units of Mathematics/ Physics, Physics/Chemistry, Biology/Chemistry, Mathematics/ Computer, and Integrated Science (double major). The combined students' scores were collated for analysis.

\subsection{Method of Data Analysis}

The data were entered and analyzed using the SPSS statistical package. Due to the nature of the data collected, ttest statistics were used to establish the significant difference in the academic achievement of Direct-Entry (DE) and NonDirect Entry (pre-NCE) students of the Niger State College of Education, Minna. In addition, the results of the examination were appraised and accepted by the academic board of the school of education, Niger State College of Education at the department and school levels including External Examiners. The t-test statistics was used because it is one of the statistical tools that best measure the performance differences of means between two samples.

\section{Results and Findings}

The data analysis and the results of the study are hereby presented below:

$\mathrm{HO}_{1}$ : There is no significant difference in the Academic Achievements of Science Students admitted into the institution through Direct Entry and Non-Direct Entry (PRE-NCE) programme at the end of NCE I at Niger State College of Education Minna.

\begin{tabular}{|c|c|c|c|c|c|c|}
\hline Mode of entry & $\mathbf{N}$ & $\mathbf{D F}$ & $\mathbf{X}$ & SD & $\mathbf{T}$ & P \\
\hline PRE - NCE & 79 & & 2.80 & 0.97 & & \\
\hline & & 368 & & & 6.93 & $0.00^{*}$ \\
\hline Direct Entry & 291 & & 2.00 & 0.89 & & \\
\hline
\end{tabular}

Table 2: T-Test Comparison of the Mean Score of Direct Entry and Non-Direct

Entry NCE Science Students at NCE I (2008) Set 1

*Significant at $\mathrm{P} \leq 0.05$ Level

Table 2 shows the result of the mean score of the Comparison of the Direct Entry and Non-Direct Entry Science Students at NCE I. It indicated that there is significant difference in the mean scores of Direct Entry (2.00) and the NonDirect Entry (2.80) at 0.05 level of significance $(\mathrm{T}=6.93>\mathrm{P}$-value $=0.00, \mathrm{DF}=368$ ). This means that there is a statistical difference in the Performance of Direct Entry and Non- Direct Entry (Pre-NCE) Science Students, the null hypothesis is rejected.

- $\mathrm{HO}_{2}$ : There is no significant difference in the academic achievements of science students who were admitted into the institution through Direct Entry and Non-Direct Entry (PRE-NCE) programme at the end of their NCE II at Niger State College of Education Minna.

\begin{tabular}{|c|c|c|c|c|c|c|}
\hline Mode of entry & $\mathbf{N}$ & $\mathbf{D F}$ & $\mathbf{X}$ & SD & T & P \\
\hline PRE - NCE & 79 & & 2.78 & 0.96 & & \\
\hline & & 368 & & & 6.92 & $0.00^{*}$ \\
\hline Direct Entry & 291 & & 1.98 & 0.90 & & \\
\hline
\end{tabular}

Table 3: T-Test Comparison of Mean Scores of Direct Entry and Non-Direct

Entry NCE Science Students at NCE II (2009) Set 1

$*$ Significant at $\mathrm{P} \leq 0.05$

Table 3 shows the result of the mean score of the Comparison of the Direct Entry and Non-Direct Entry Science Students at NCE II. It indicates that there is significant difference in the mean scores of Direct Entry (1.98) and the NonDirect Entry (2.78) at 0.05 level of significance $(\mathrm{T}=6.92>\mathrm{P}$-value $=0.00, \mathrm{DF}=368)$. Therefore, this means that there is a 
statistical difference in the Performance of Direct Entry and Non- Direct Entry (Pre-NCE) Science Students, the null hypothesis is rejected

- $\mathrm{HO}_{3}$ : There is no significant difference in the Academic Achievements of Science Students who were admitted into the institution through Direct Entry and Non - Direct Entry (PRE - NCE) programme at the end of their NCE III at Niger State College of Education Minna.

\begin{tabular}{|c|c|c|c|c|c|c|}
\hline Mode of entry & $\mathbf{N}$ & $\mathbf{D F}$ & $\mathbf{X}$ & SD & $\mathbf{T}$ & $\mathbf{P}$ \\
\hline PRE - NCE & 79 & & 2.80 & 0.97 & & \\
\hline & & 368 & & & 7.39 & $0.00^{*}$ \\
\hline Direct Entry & 291 & & 1.95 & 0.89 & & \\
\hline
\end{tabular}

Table 4: T-Test Comparison of the Mean Score of Non - Direct Entry and Direct Entry NCE Science Students at NCE Iii (2010) Set 1 *Significant at $\mathrm{P} \leq 0.05$

Table 4 shows the result of the mean score of the Comparison of the Direct Entry and Non-Direct Entry Science Students at NCE III. From table 4, it indicates that there is significant difference in the mean scores of Direct Entry (1.95) and the Non-Direct Entry (2.80) at 0.05 level of significance ( $\mathrm{T}=7.39>\mathrm{P}$-value $=0.00, \mathrm{DF}=368)$. Therefore, this means that there is a statistical difference in the Performance of Direct Entry and Non- Direct Entry (Pre-NCE) Science Students, the null hypothesis is rejected.

\section{Discussion of Findings}

The study was designed to compare the academic achievement of students by mode of entry into the school of sciences of the Niger State College of Education, Minna. Findings from this study show that the Non-Direct Entry students achieved significantly higher than their counterparts of the Direct-Entry students in their NCE I, NCE II, and NCE III results. The finding is contrary to the previous work of Majasan and Bakare, (1997), Idika (1997) who found no significant relationship between entry qualification and performance in the final NCE III Examination. Similarly, these findings affirm Nwajei (1990) that stated that entry qualification is a poor prediction of academic performance and the degree of performance cannot be related to entry qualification alone. Afolabi (2005) stated that individual performance might be due to some factors such as the availability of necessary materials. He equally found no significant relationship between entry qualification and college students' performance in micro-teaching.

As highlighted by Dahiru, (2010) when he compared the academic achievement in science of Non-Direct Entry and Direct Entry Nigeria Certificate in Education students, that there is no significant difference in the Academic Achievement between Direct Entry and Non-Direct Entry science students at the end of their NCE proramme. This contrasts the view of the findings in this study.

\section{Conclusion and Recommendations}

In conclusion, the study found significant differences between the mean scores of academic achievements of Direct Entry and Non-direct entry (Pre-NCE) NCE I, NCE II, and NCE III students in the school of sciences at the Niger State College of Education, Minna.

On the basis of the findings and conclusions of this study, the following recommendations are made;

- Admission of Non-Direct Entry science students should be enhanced so as to boost enrollment thereby increasing the number of qualified NCE science teachers. That is students with O'level deficiency should be admitted to NonDirect Entry science provided they fulfilled NCCE Pre NCE minimum entry requirements as those students who were admitted through Pre-NCE were able to sustain impressive performance.

- Parents should not discourage their wards towards Non-Direct Entry NCE programme through proper enlightenment and counselling.

- Science-based teachers should be encouraged to be attending conferences, seminars and workshops to keep themselves updated with new teaching strategies for better result.

- Provision of counselling for students to help in motivating those showing poor performance in school.

- The Post-Jamb test introduced by colleges of Education should be sustained especially as cases of students having a GPA of 0.00 have been recorded among UTME students who came in Direct.

\section{References}

i. Ado, I.K (2010). Gender Performance difference in Mathematics and other Science Subjects at Polytechnic. Journal of Educational Research and Development 5(1), 51-55

ii. Adonis, L. (2005). "Better schools better results" in (Alonge, M.F. 2005). Assessment and future of schooling and learning - Keynote address presented at the 31st Annual Conference of International Association of Educational Assessment held at Abuja, Nigeria.

iii. Afolabi, A.O. (2005). Entry Qualification As a prediction of college students' performance in microteaching Ife. Journal of Curriculum Studies 2(2), 60-69

iv. Akinbote O. (2007). Problem of teaching education for primary schools In Nigeria: Beyond Curriculum design and implementation. International Journal of African \& African American Students 6(2), 64 - 71. 
v. Dahiru, S.Y. (2010). Comparative study of Academic Achievement in Science of Direct-Entry and Non-Direct Entry Nigeria Certificate in Education Students. Journal of Education Research and Development. 5 (1) 89-94.

vi. Idika, N. (2003). The Relationship between entry qualification and final performance in the Nigeria Certificate in Education (technical) programme. Journal of Educational Review 7(2), 255-257.

vii. Erinosho, Y. E. (2005). Women and Science.36th Inaugural lecture. Olabisi Onabanjo University, Agoiw oye, 1 - 37

viii. Lawal, A.N. (2000). The relationship of entry qualification and sex to academic performance of NCE graduates of Kano State College of Education, Jigawa. Journal of Education 1(2), 1-9.

ix. Lawal, N., Badu, J. B., \& Chukwuemeka, E. J. (2015). Predictive validity of first year GPA and final degree classification among management and social sciences students. The International Journal of Science and Technoledge, 3(7), 210.

x. Majasan, J.A. \& Bakare, G.C.M. (2007). Entry Qualification Journal of African Educational Research.

xi. National Commission for Colleges of Education (2007). Minimum Standard for NCE Teacher Education, Abuja: NCC PR \& XS.

xii. National Commission for Colleges of Education (2009). Minimum Standard for NCE Teacher Education, Abuja: NCCE PR \& XS.

xiii. Nwajei, T.A. (2001). The Relationship Between Entry Qualification and Academic Success in Accounting Education. Unpublished NCE Project. FCE (T). Asaba.

xiv. NUC (National University Commission). (2005). Draft benchmark minimum academic standards for Education in Nigerian Universities. Abuja: Government Press.

xv. Okebukola, P. (2007) science, Technology and mathematics for sustainable development, key note address presented at the Golden Jubilee anniversary of Nigeria Sokoto.

xvi. Oluwatayo, J.A., (2003). Model of entry and performance of undergraduates in science courses in Nigeria universities. Unpublished Ph. D thesis. University of Ado-Ekiti, Ado-Ekiti, pp:56-60.

xvii. Omwirhiren, E.M. (2002). The relative effects of individualised instructional and Traditional method of Teaching on Gender Achievement in SSCE Chemistry. Paper presented at the $4^{\text {th }}$ National Conference of the School of Education, Federal College of Education, and Kano 2 ${ }^{\text {nd }}-6^{\text {th }}$ September 2003.

xviii. Quadri, K. \& Olowo, G.M. (2013). Academic Performance of Direct and Pre-NCE Students in Federal College of Education. Educational Administrators Research Journal in Organisational Psychology and Educational Studies 2(4) 218-223.

xix. Samuel, K. (2012). Correlational Analysis of Students Entry Qualifications and Academic Performance in partial certification of Education in Chemistry at Federal College of Education Zaria. Postgraduate Seminar Series 1(1), 93-98.

xx. Simon, V.I. \& Nancy N.A. (2010). Comparative Analysis of Academic Achievement of UME and Ex-remedial students: Case study of University of Agriculture, Makurdi, Nigeria: Journal of Education Administration and Policy Studies 2 (1), 009-030. 